\title{
Kitosan-şeker pancarı posası biyokompozit sorban sisteminin anyonik boyarmadde biyosorpsiyon potansiyeli
}

\author{
Anionic dye biosorption of potential of chitosan-sugar beet pulp biocomposite sorbent \\ system
}

\author{
Sema ÇELIK *1,a \\ ${ }^{1}$ Eskişehir Osmangazi Üniversitesi, Fen Edebiyat Fakültesi, Kimya Bölümü, 26040, Eskişehir, Türkiye
}

• Geliş tarihi / Received: 05.05.2020 • Düzeltilerek geliş tarihi / Received in revised form: 18.01.2021 • Kabul tarihi / Accepted: 25.01 .2021

\begin{abstract}
Öz
Bu çalışmada endüstriyel bir atık olan şeker pancarı posası kitosan ile immobilize edilmiş ve elde edilen biyokompozit materyal sulu çözeltilerden Asit Kırmızısı 1 ve Reaktif Kırmızısı 2 boyarmaddelerinin giderimi için kullanılmıştır. Biyokompozit sorbanın renk giderim performansı, başlangıç çözelti pH'sı, sorban miktarı, başlangıç boyarmadde derişimi, denge süresi ve iyonik şiddetin bir fonksiyonu olarak incelenmiştir. Optimum biyosorpsiyon koşullarında (pH: 3.0, biyokompozit sorban miktarı: $0.01 \mathrm{~g}$, denge süresi: $10 \mathrm{dk}$ ) biyokompozitin boyarmadde giderim verimleri AK1 için $\% 81.23$, RK2 için ise \%86.79 olarak kaydedilmiştir. Biyokompozit sistemin renk giderim dinamikleri kinetik ve izoterm modellemeleriyle incelenmiştir. Biyosorpsiyon prosesi en iyi yalancı birinci derece kinetik modeli ve Langmuir izoterm modeli ile tanımlanmıştır. Biyokompozitin maksimum tek tabakalı biyosorpsiyon kapasitesi Asit Kırmızısı 1 için 358.027 $\mathrm{mg} \mathrm{g}^{-1}$, Reaktif Kırmızısı 2 için ise $379.228 \mathrm{mg} \mathrm{g}^{-1}$ olarak hesaplanmıştır. Boyarmadde-biyokompozit sorban olası etkileşimleri zeta potansiyeli, IR ve SEM analizleriyle karakterize edilmiştir. Sonuçlar, geliştirilen biyokompozit sorbanın oldukça yüksek renk giderim kapasitesi ile sulu ortamdan anyonik boyarmadde uzaklaştırılması için etkili bir alternatif olabileceğini göstermiştir.
\end{abstract}

Anahtar kelimeler: Biyosorpsiyon, Boyarmadde arıtımı, İmmobilizasyon, Kitosan, Şeker pancarı

\begin{abstract}
In this study, sugar beet pulp industrial waste was immobilized with chitosan and the obtained biocomposite material was used to remove Acid Red 1 and Reactive Red 2 dyes from aqueous solutions. Decolorization potential of biocomposite sorbent was examined as a function of initial solution $\mathrm{pH}$, sorbent amount, initial dye concentration, time, and ionic strength. The dye removal efficiency of biocomposite at optimum biosorption conditions ( $p H$ : 3.0, biocomposite amount: $0.01 \mathrm{~g}$, time: $10 \mathrm{~min}$ ) was recorded as 81.23\% for Acid Red 1 and 86,79\% for Reactive Red 2. Decolorization dynamics of biocomposite system were investigated isotherm and kinetic modeling. The biosorption process is well described by the pseudo-first-order kinetic model and the Langmuir isotherm model. The maximum biosorption capacity of biocomposite was calculated as $358.027 \mathrm{mg} \mathrm{g}^{-1}$ for Acid Red 1 and $379.228 \mathrm{mg} \mathrm{g}^{-1}$ for Reactive Red 2. Possible dyebiocomposite interactions were characterized by zeta potential, IR, and SEM analysis. The results showed that the suggested biocomposite sorbent can be an effective alternative biomaterial for the removal of anionic dye from aqueous media with a high color removal capacity.
\end{abstract}

Keywords: Biosorption, Dye treatment, Immobilization, Chitosan, Sugar pulp

*a Sema ÇELiK; secelik@ogu.edu.tr, Tel: (0222)239 37 50, orcid.org/0000-0003-4284-823X 


\section{Giriş}

Endüstriyel uygulamalar ve ekonominin gelişmesiyle birlikte, doğal kaynakların kullanımı hızla artmış, beraberinde su kirliliği önemli problemlerden biri haline gelmiştir. Özellikle tekstil endüstrisi gibi pek çok alanda yaygın olarak kullanılan sentetik boyarmaddeleri içeren atık suların kontrolsüz şekilde sucul ortamlara salınması ve bu organik kirleticilerin su kaynakları üzerinde neden olduğu kirlilik küresel anlamda bir çevre sorunu teşkil etmektedir (An vd., 2008; Zhou vd., 2019). Boyarmaddeler gibi organik kirleticilerle kontamine olmuş endüstriyel atık suların temizlenmesinde çeşitli biyolojik, kimyasal ve fiziksel yöntemler tek başlarına ya da birlikte geleneksel olarak kullanılmaktadır. Ancak bu yöntemler yüksek maliyetleri, atık çamur üretmeleri ve tek başlarına boyarmaddelerin giderilmesinde yetersiz kalabilmeleri gibi dezavantajlara da sahiptir.

Geleneksel yöntemlere alternatif olarak öne çıkmaya başlayan biyosorpsiyon yöntemi ise uygulama pratikliği, ekonomikliği ve yüksek verim sağlayabilmesi gibi önemli özelliklerinden dolayı son yıllarda ilgi odağı haline gelmiş̧tir (Barka vd., 2011; Bouras vd., 2017). Endüstriyel kökenli atıklar, aktif çamur, mikrobiyal biyokütleler gibi çeşitli biyolojik materyaller zengin fonksiyonel grup içerikleriyle bu alanda yaygın olarak kullanılan ekonomik biyosorbanlardır (Wase vd., 1997; Safa ve Bhatti, 2011; Rangabhashiyam vd., 2013; Nawaz vd., 2014; Khan vd., 2019).

Biyosorpsiyon uygulamalarında biyosorbanlar serbest ya da immobilize formda kullanılmaktadır. İmmobilize biyokütle sistemleri, bir desteğe veya taşıyıcıya bağlanmış, hareket kabiliyetleri kısıtlanmış olan ve toksik kirleticilerin arıtımında etkili olduğu bilinen sorbanları ifade etmektedir. Çalışmaların çoğu biyokütlelerin sentetik ve doğal polimer türevleri gibi taşıyıcı yüzeylere tutturulması üzerine odaklanmıştır. Taşıyıcı olarak akrilamid, poliüretan, polivinil, reçineler, aljinat, agar, agaroz ve kitin türevi kitosan gibi yapılar kullanılmaktadır (de-Bashan ve Bashan, 2010; Girijan ve Kumar, 2019). İmmobilize formdaki biyosorbanlar, mekanik kararlılıkları, çözeltiden daha kolay ayrlabilmeleri ve tekrar kullanılabilmeleri gibi özellikleriyle son y1llarda yaygın olarak çalışılmaktadır (ud Din vd., 2016). İmmobilizasyon destek malzemeleri arasında yer alan amino ve hidroksil fonksiyonel gruplarını içeren kitosan, boyarmaddelerin sorpsiyonunda önemli rol oynamaktadır. Boyarmadde içerikli atık suların arıtımında kitosan destekli sorbanların kullanılması, son yıllarda ilgi odağı haline gelmiştir (Crini ve Badot, 2008; Vakili vd., 2014; Subramani ve Thinakaran, 2017; Şenol vd., 2020).

Şeker üretim prosesi atığı olan şeker pancarı posasindan yeni bir immobilize biyosorban materyal geliştirilmesi ve büyük ölçüde hayvan yemi olarak kullanılmakta olan bu düşük maliyetli endüstriyel atığın alternatif bir kullanım alanında değerlendirilmesi bu çalışmanın amacını oluşturmaktadır. Literatürde bu atık biyokütlenin arıtım amacına yönelik kullanımlarıyla ilgili bazı çalışmalarda daha çok doğal (Dronnet vd., 1997; Özer vd., 1998; Aksu ve İşoğlu, 2005; Pehlivan vd., 2006; Vučurović vd., 2012) ya da aktif karbona dönüştürülmüş formları (Demiral ve Gündüzoğlu, 2010; Castro vd., 2017) ya da kimyasal muamelesine dayalı yüzey modifikasyonu ile hazırlanmış formları (Altundogan vd., 2007; Tunali Akar vd., 2013; Arslanoğlu ve Tümen, 2015) önerilmektedir. Bu materyalin kitosan ile immobilizasyonu sonucu hazırlanan biyokompozitin anyonik boyarmadde biyosorpsiyon karakteristikleri ile ilgili bir çalışmaya ise rastlanmamıştır.

$\mathrm{Bu}$ çalışmada aktif immobilizasyon yöntemiyle geliştirilen şeker pancarı posası-kitosan biyokompozit sorban materyali ile sulu ortamdan endüstriyel boyarmaddelerden Asit Kırmızıs1 1 (AK1) ve Reaktif Kırmızıs1 2 (RK2)'nin giderim karakteristikleri araştırılmıştır. Biyokompozit miktarı, çözeltinin başlangıç pH'sı, başlangıç boyarmadde derişimi, denge süresi ve iyonik şiddet gibi biyosorpsiyonu etkileyen parametreler incelenmiş ve biyosorpsiyon dinamikleri kinetik ve izoterm eşitlikleri ile değerlendirilmiştir. Olası biyomateryal-boyarmadde etkileşimleri SEM, IR analizleri, Boehm titrasyonu ve zeta potansiyeli ölçümü yöntemleri ile incelenmiştir.

\section{Materyal ve metot}

\subsection{Biyokompozit sorbanin hazırlanmast}

İmmobilize edilecek şeker üretim prosesi atığı olan şeker pancarı posası saf su ile yıkandıktan sonra $70^{\circ} \mathrm{C}$ 'de etüvde kurutulup, ögütülmüss ve $212 \mu \mathrm{m}$ tanecik boyutlu elekten geçirilerek immobilizasyona hazır hale getirilmiştir. İmmobilizasyon işleminde $1.5 \mathrm{~g}$ kitosan $60 \mathrm{~mL}$ $\% 5$ 'lik $\mathrm{CH}_{3} \mathrm{COOH}$ çözeltisinde çözülmüş ve bu çözeltiye $1.5 \mathrm{~g}$ toz şeker pancarı biyokütlesi ilave edilip homojen bir süspansiyon hazırlanmıştır. $\mathrm{Bu}$ süspansiyon $500 \mathrm{~mL} 0.5 \mathrm{M} \mathrm{NaOH}$ çözeltisi içerisine damlatılarak boncuklar oluşturulmuştur (Ngah vd., 2005). Böylece oluşturulan 
biyokompozit birkaç defa yıkanmış ve $70^{\circ} \mathrm{C}$ 'de etüvde kurutulduktan sonra öğütülerek biyosorpsiyon çalışmalarında kullanılmıştır.

\subsection{Reaktif ve çözeltiler}

Hedef kirleticiler olarak seçilen AK1 (Kimyasal formül: $\mathrm{C}_{18} \mathrm{H}_{13} \mathrm{~N}_{3} \mathrm{Na}_{2} \mathrm{O}_{8} \mathrm{~S}_{2}$, molekül ağırlığı: 509,42 $\mathrm{g} \mathrm{mol}^{-1}$ ) ve RK2 (Kimyasal formül: $\mathrm{C}_{19} \mathrm{H}_{10} \mathrm{Cl}_{2} \mathrm{~N}_{6} \mathrm{Na}_{2} \mathrm{O}_{7} \mathrm{~S}_{2}$, molekül ağırlı̆ğ $615,33 \mathrm{~g}$ $\mathrm{mol}^{-1}$ ) boyarmaddeleri Sigma-Aldrich ticari ürünleridir. Her iki boyarmadde sodyum tuzu formunda olup, suda çözündüklerinde anyonik yapıya dönüşmektedir. AK1 ve RK2 boyarmaddelerinin molekül yapıları Şekil 1'de verilmiştir.<smiles>CC(=O)Nc1cc(S(=O)(=O)O[Na])cc2cc(S(=O)(=O)O[Na])c(N=Nc3ccccc3)c(O)c12</smiles>

AK1<smiles>[NH3+]OS(=O)(=O)c1cc(Nc2nc(Cl)nc(Cl)n2)c2c(O)c(N=Nc3ccccc3)c(S(=O)(=O)O[Na])cc2c1</smiles>

RK2

Şekil 1. AK1 ve RK2 boyarmaddelerinin molekül yapıları

Boyarmaddelerden gerekli miktarlar tartılarak $1000 \mathrm{mg} \mathrm{\textrm {L } ^ { - 1 }}$ derişiminde stok çözeltiler hazırlanmıştır. Çalışmalar için kullanılan diğer derişimlerdeki boyarmadde çözeltileri bu stok çözeltilerin seyreltilmesiyle hazırlanmıştır. Çözeltilerin $\mathrm{pH}$ değerlerinin ayarlanmasında ise 1 M $\mathrm{HCl}$ ve/veya $1 \mathrm{M} \quad \mathrm{NaOH}$ çözeltileri kullanılmıştır.

\subsection{Biyosorpsiyon çalışmaları}

Hazırlanan doğal ve biyokompozit sorbanlar ile AK1 ve RK2 boyarmaddelerinin biyosorpsiyon ön denemeleri sonunda biyokompozit sorban ile çalışmalara devam edilmiştir. Kesikli sistem biyosorpsiyon deneyleri $100 \mathrm{~mL}$ 'lik beherler içerisinde $25 \mathrm{~mL} 100 \mathrm{mg} \mathrm{L}^{-1}$ AK1 ve RK2 çözeltileri ile 300 devir $\mathrm{dk}^{-1}$ karıştırma hızındaki çoklu manyetik karıştırıcılar üzerinde gerçekleştirilmiştir. Boyarmaddelerin biyosorpsiyon ön denemeleri $\mathrm{pH} 3.0$ ve $0.025 \mathrm{~g}$ biyosorban miktarıyla yapılmıştır. Çözeltilerin başlangıç $\mathrm{pH}$ değerlerinin AK1 ve RK2 biyosorpsiyon verimleri üzerine etkisini belirlemek için 3.0-10.0 aralığında değişen $\mathrm{pH}$ değerlerinde çalışılmıştır. Renk giderimine kompozit miktarının etkisi ise en uygun başlangıç $\mathrm{pH}$ değerinde 0.001-0.025 g aralığında değişen biyosorban miktarları ile incelenmiştir. Biyosorpsiyon denge süresi 5-60 dk aralığında, biyosorpsiyona başlangıç boyarmadde derişimi etkisi ise her iki boyarmaddenin derişimi $25-400 \mathrm{mg} \mathrm{L}^{-1}$ aralığında değiştirilerek incelenmiştir. Renk giderimine biyosorpsiyon ortamındaki iyonik şiddetin etkisi, en uygun biyosorpsiyon koşullarında $0.02-0.2 \mathrm{~mol}$ $\mathrm{L}^{-1}$ derişim aralığında $\mathrm{KNO}_{3}$ içeren $\mathrm{AK} 1$ ve RK2 çözeltileri ile çalışılmıştır. Biyosorpsiyon süreci sonunda biyokompozit sorban, çözeltiden santrifüjleme (5000 devir $\left.\mathrm{dk}^{-1}\right)$ ile ayrılmış, çözeltide kalan boyarmadde derişimleri, UV spektrofotometresi (Shimadzu UV-2550) ile AK1 ve RK2 için sirasıyla $404 \mathrm{~nm}$ ve $468 \mathrm{~nm}$ maksimum dalgaboylarında tayin edilmiştir.

Deneysel çalışmalar üç kez tekrarlanmış olup ve deney verileri aritmetik ortalamalar alınarak istatistiksel olarak \%95 güven aralığında değerlendirilmiştir. Sonuçlar biyosorpsiyon kapasitesi $\left(q_{e}\right)$ ve biyosorpsiyon verimi (\%) cinsinden aşağıda verilen eşitlikler (Eşitlik 1 ve Eşitlik 2) kullanılarak hesaplanmıştır:

$$
\begin{aligned}
& q_{d}=\frac{C_{o}-C_{d}}{m} \times V \\
& \% \text { Biyosorpsiyon }=\frac{C_{o}-C_{d}}{C_{o}} \times 100
\end{aligned}
$$

Burada;

$q_{d}$ : Biyosorpsiyon kapasitesi $\left(\mathrm{mg} \mathrm{g}^{-1}\right)$,

$C_{0}$ : Çözelti ortamındaki başlangıç boyarmadde derişimi (mg L $\left.{ }^{-1}\right)$

$C_{\mathrm{d}}$ : Biyosorpsiyon sonrası çözelti ortamındaki boyarmadde derişimi $\left(\mathrm{mg} \mathrm{L}^{-1}\right)$

$m$ : Biyokompozit sorban miktarı (g), 
$V$ : AK1 ve RK2 boyarmadde çözeltilerinin hacmidir (L).

\subsection{Biyokompozit sorbanin karakterizasyonu}

Biyokompozit sorban zeta potansiyeli (Malvern Zetasizer), FTIR (Bruker TENSOR 27), SEM (JEOL 560 LV SEM) analizleri ile incelenmiş olup, biyosorbanın yüzey asidik ve bazik grupları Boehm titrasyonu ile belirlenmiştir.

\section{Bulgular ve tartışma}

Öncelikle şeker pancarı posasından hazırlanan doğal ve kitosan ile immobilize edilen biyokompozit sorbanın AK1 ve RK2 için biyosorpsiyon verimleri incelenmiş ve elde edilen sonuçlar Şekil 2'de sunulmuştur.

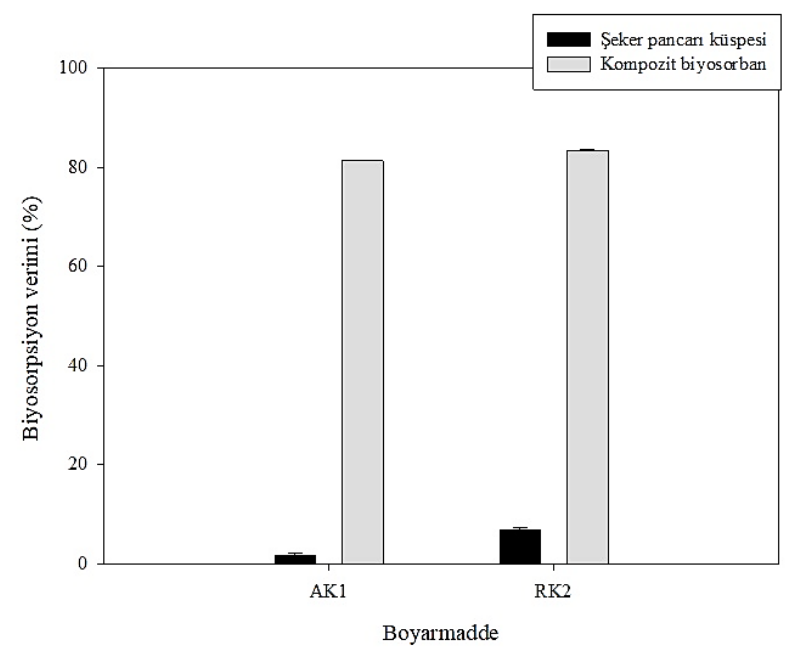

Şekil 2. Doğal ve biyokompozit sorbanın AK1 ve RK2 boyarmaddeleri için biyosorpsiyon performanslar1.

Şekil 2'de görüldügü üzere doğal ve biyokompozit sorbanlarin biyosorpsiyon verimleri kıyaslandığında AK1 ve RK2 boyarmaddeleri için doğal biyosorbanın biyosorpsiyon verimlerinin sirasiyla \%1.70 ve $\% 6.85$, biyokompozit sorbanın biyosorpsiyon verimlerinin ise sirasiyla $\% 81.37$ ve \%83.34 olduğu görülmektedir. Kitosan ile immobilizasyon işlemi sonunda doğal biyokütlenin biyosorpsiyon veriminin AK1 için yaklaşık 47 kat RK2 için ise yaklaşık 12 kat arttı̆̆ belirlenmiş $(p<0.05)$ ve çalışmalara biyokompozit sorban ile devam edilmiştir.

\subsection{Başlangıç çözelti pH'sının AK1 ve RK2 giderimine etkisi}

Biyokompozit sorban ile AK1 ve RK2 boyarmaddelerinin giderimine başlangıç $\mathrm{pH}$ 's1 etkisinin incelenmesinde, farklı başlangıç $\mathrm{pH}$ değerlerinde çözeltiler kullanılmış ve elde edilen sonuçlar Şekil 3a'da verilmiştir. Yine çalışılan bu $\mathrm{pH}$ değerlerinde biyokompozit sorbanın zeta potansiyeli ölçümleri gerçekleştirilmiş ve sonuçlar Şekil 3b'de sunulmuştur.

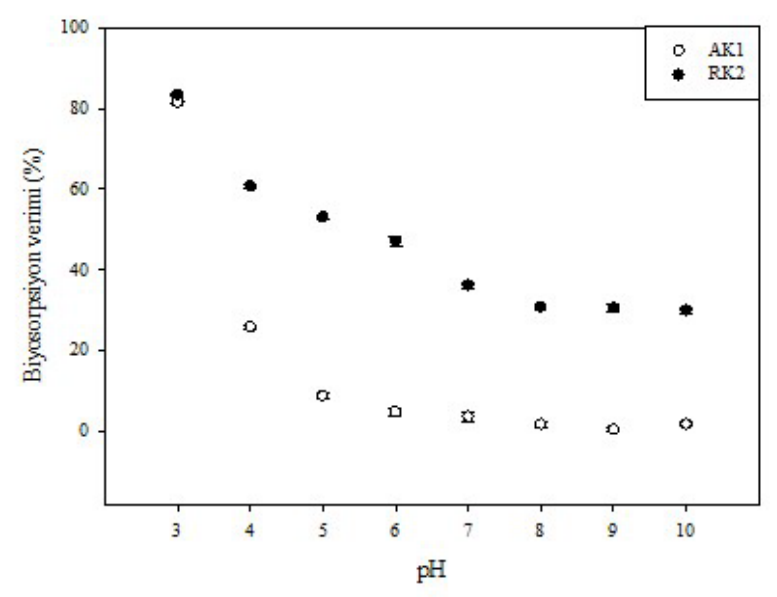

(a)

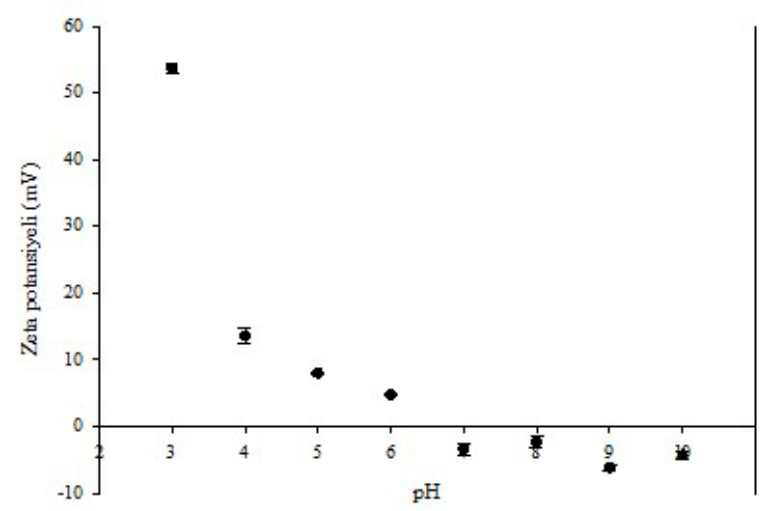

(b)

Şekil 3. Değişen pH'larda biyokompozit sorbanın AK1 ve RK2 boyarmaddeleri için biyosorpsiyon verimleri (a) ve zeta potansiyel değerleri (b).

Şekil 3a'daki sonuçlara göre biyokompozit sorbanın her iki boyarmadde için en yüksek biyosorpsiyon verimine $\mathrm{pH} \quad 3.0^{\prime}$ 'te ulaştığ görülmektedir. Ortam pH'sinın 3.0'dan 4.0'a artmasiyla biyosorpsiyon veriminde düşüş gözlenmeye başlanmış ve bu eğilim $\mathrm{pH}$ artışıyla birlikte devam etmiştir $(p<0.05)$. Biyokompozit sorbanın asidik $\mathrm{pH}$ değerlerinde yüksek biyosorpsiyon performans1, düşük $\mathrm{pH}$ değerlerinde protonlanmış biyokompozit sorban fonksiyonel grupları ile anyonik karakterli boyarmadde molekülleri arasındaki elektrostatik çekim kuvvetleri ile açıklanabilir. Biyosorpsiyon ortamının pH'sı arttıkça, biyokompozit sorbanın yüzeyindeki negatif yük yoğunluğu da artmakta, bu kez biyokompozit sorban ile anyonik boyarmadde 
molekülleri arasındaki itme kuvvetleri biyosorpsiyon verimini azaltmaktadır. Bu bulgular biyokompozit sorbanın zeta potansiyeli ölçümü çalışmaları ile de desteklenmektedir. Şekil 3b incelendiğinde biyokompozit sorbanın en yüksek pozitif yüzey yüküne biyosorpsiyon için en uygun $\mathrm{pH}$ olarak belirlenen $\mathrm{pH} 3.0$ 'da sahip olduğu görülmektedir. Yine her iki boyarmadde için de $\mathrm{pH}$ 7.0-10.0 aralığında gözlenen düşük biyosorpsiyon verimleri biyokompozit sorbanın yüzey yükünün negatif olduğu aralıkta gerçekleşmiştir. pH'a bağlı benzer biyosorpsiyon süreci farklı anyonik boyarmaddeler için de bildirilmiştir (Akkaya ve Özer, 2005; Yang vd., 2011).

\subsection{Biyokompozit sorban miktarinin $A K 1$ ve RK2 giderimine etkisi}

Biyosorpsiyonu etkileyen önemli bir diğer parametre de biyosorpsiyonda kullanilan biyosorban miktarıdır. Şekil 4'te AK1 ve RK2 boyarmaddelerinin giderimine biyokompozit sorban miktarının etkisi verilmiştir.

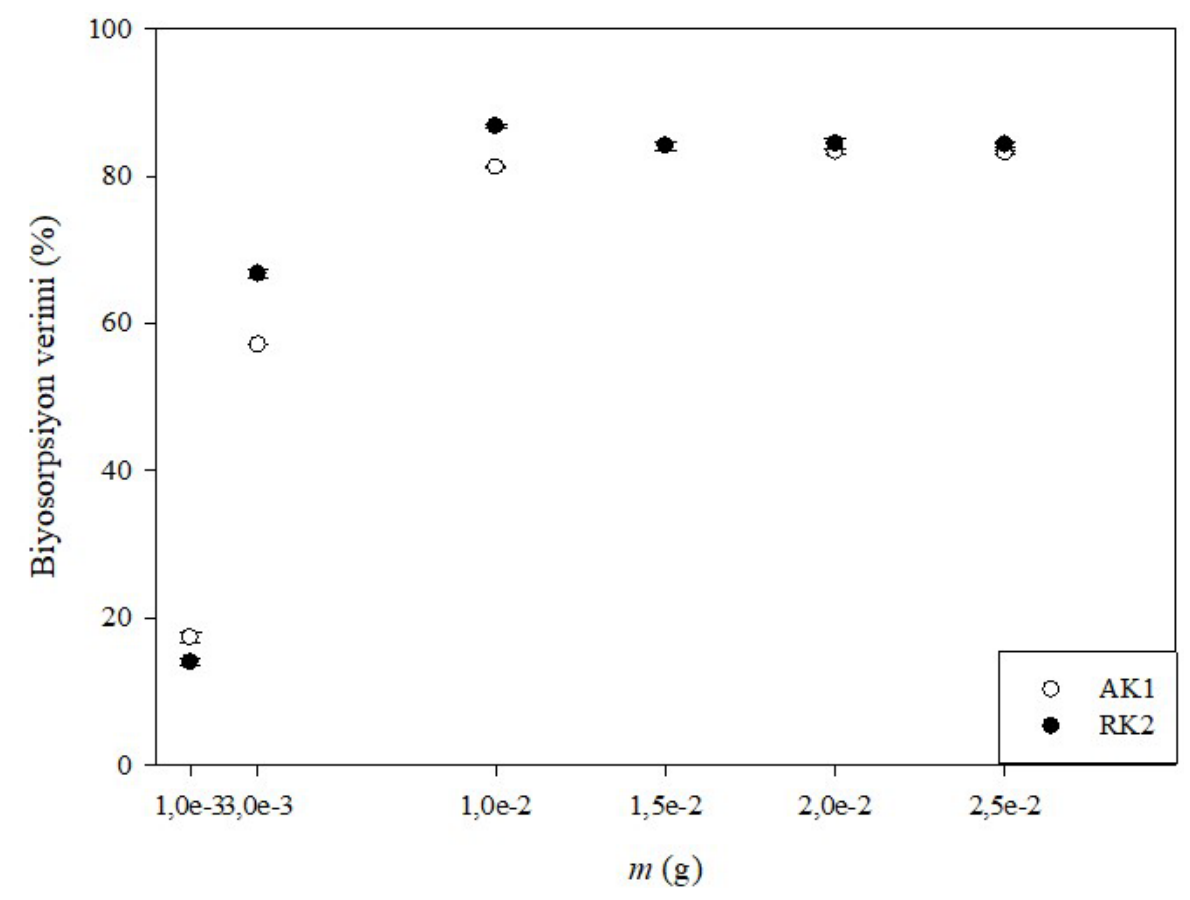

Şekil 4. AK1 ve RK2 boyarmaddelerinin giderimine biyokompozit sorban miktarının etkisi.

Şekil 4 incelendiğinde gibi biyokompozit sorban miktarının 0.001 g' dan 0.01 g'a artmasıyla her iki boyarmadde için de biyosorpsiyon verimlerinin önemli ölçüde arttığı görülmektedir. Bu aralıkta AK1 için biyosorpsiyon verimi \%17.31'den \%81.23'e; RK2 için ise \%13.95'ten \%86.79'a yükselmiştir $(\mathrm{p}<0.05)$. Her iki boyarmadde için biyokompozit sorban miktarının 0.01 g'dan 0.025 g'a çıkarılması durumunda ise biyosorpsiyon verimlerinde değişiklik gözlenmemiştir ( $p>0.05$ ). $\mathrm{Bu}$ durum, biyokompozit sorban miktarının artmasına bağlı olarak AK1 ve RK2 moleküllerinin bağlanabileceği yüzey alanının da artması ve belli bir miktardan sonra da sabit çözelti hacmi ve derişiminde bulunan boyarmadde molekülleri ile biyosorban yüzeyinin doygunluğa ulaşması ile açıklanabilmektedir. Bu bulgular literatürede farklı boyarmaddelerin biyosorpsiyonu için bildirilmiş olan ilgili sonuçlarla (Kumari vd Abraham, 2007; Akar vd., 2013) uyum içerisindedir.

\subsection{Kinetik çalışmaları}

AK1 ve RK2 boyarmaddelerinin biyokompozit sorban üzerine biyosorpsiyonunun süreye bağl1 değişimi ve doğrusal olmayan regresyon analizleri Şekil 5'te verilmiştir. 


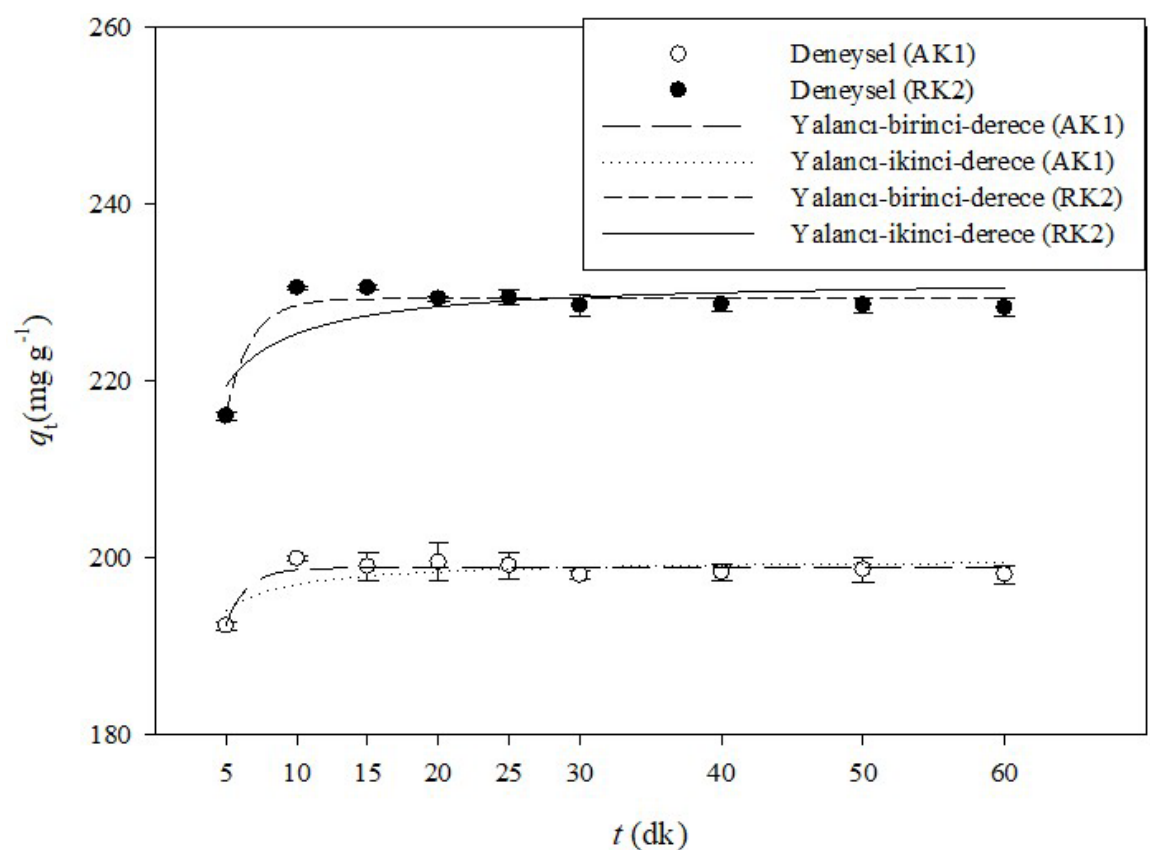

Şekil 5. Biyokompozit sorban ile AK1 ve RK2 biyosorpsiyonunun süreye bağlı değişimi ve doğrusal olmayan regresyon analizleri.

Şekil 5 incelendiğinde biyokompozit sorbanın biyosorpsiyon kapasitesi her iki boyarmadde için de ilk $10 \mathrm{dk}$ içinde hılı bir artış göstermiş ve bu süreden sonra biyosorpsiyon kapasitelerinde bir değişiklik gözlenmemiştir ( $\mathrm{p}>0.05$ ). Biyosorpsiyon dengesinin kurulduğu 10 . $\mathrm{dk}$ da biyokompozit sorban AK1 için $199.89 \mathrm{mg} \mathrm{g}^{-1}$; RK2 için ise

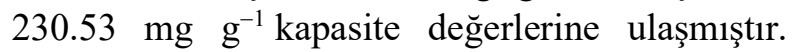
Sürecin pratik uygulamaları açısından bu kısa denge süresi önemli bir avantaj olarak değerlendirilebilir. Biyosorpsiyon sürecinin dinamiğini ve kontrol mekanizmasını araştırmak için elde edilen kinetik veriler Lagergren'in yalanc1-birinci-derece kinetik modeli (Lagergren, 1898) ve yalanc1-ikinci-derece kinetik modelinin doğrusal olmayan eşitlikleri (Ho ve McKay, 1999) ile değerlendirilmiştir. Bu kinetik modellere ait eşitlikler aşağıda verilmiştir:
Lagergren yalanc1-birinci-derece kinetik modeli:

$$
q_{\mathrm{t}}=q_{\mathrm{d}}\left(1-e^{-k_{1} t}\right)
$$

Yalanc1-ikinci-derece kinetik modeli:

$$
q_{\mathrm{t}}=\left(\frac{k_{2} q_{\mathrm{d}}^{2}}{1+k_{2} q_{\mathrm{d}}^{2} t}\right)
$$

Burada $q_{\mathrm{t}}$ ve $q_{\mathrm{d}}$ biyokompozit sorban materyalin sirasiyla $t$ zamanındaki ve dengedeki biyosorpsiyon kapasitesini $\left(\mathrm{mg} \mathrm{g}^{-1}\right), k_{1}\left(\mathrm{dk}^{-1}\right)$ ve $k_{2}$ $\left(\mathrm{g} \mathrm{mg}^{-1} \mathrm{dk}^{-1}\right)$ yalanc1-birinci-dereceden ve yalanc1ikinci-dereceden kinetik modelleri için hız sabitlerini belirtmektedir. Bu kinetik modellerine ait parametreler Tablo 1'de sunulmuştur.

Tablo 1. Biyokompozit sorban ile AK1 ve RK2 biyosorpsiyonlarına ait kinetik parametreleri

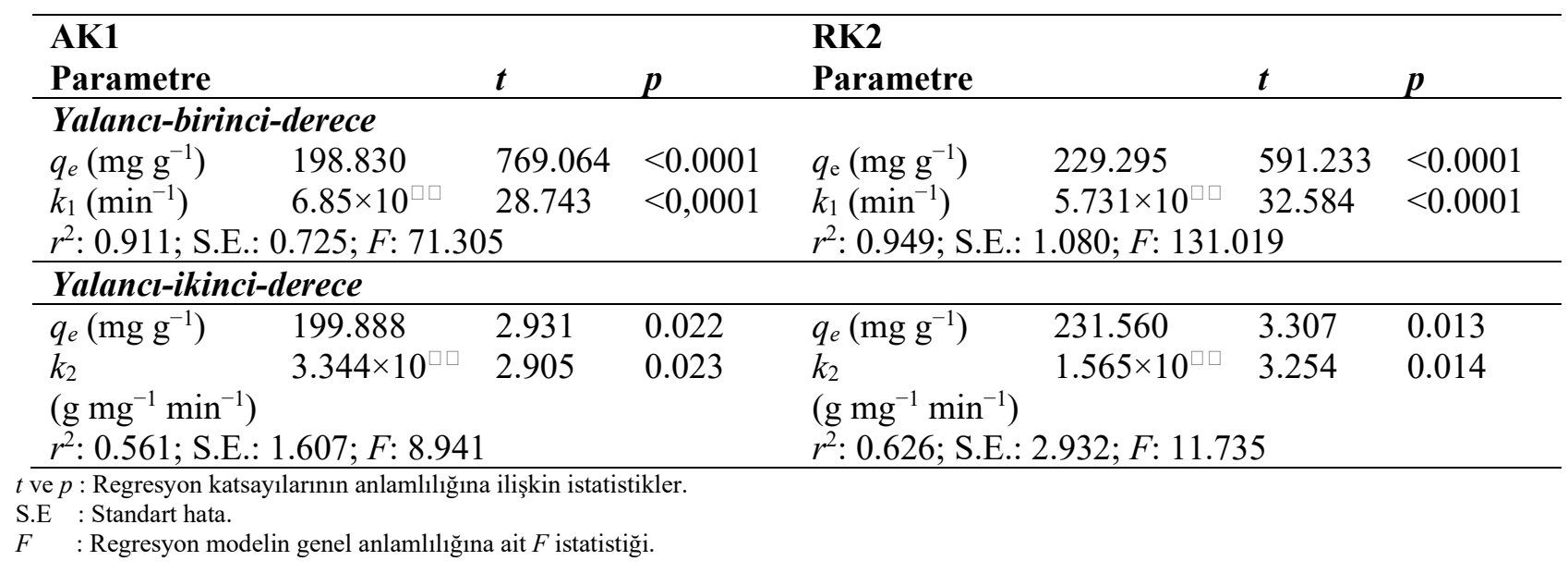


Tablo 1'de $r^{2}$ ve $F$ değerleri karşılaştırıldığında AK1 ve RK2 biyosorpsiyon süreçlerinin için daha çok yalanci-birinci-derece kinetik modeline uyum sağladığı görülmüş̧ür $(\mathrm{p}<0.05)$. Ayrıca S.E ve $p$ değerlerinin de bu modeli doğruladığı söylenebilir. $\mathrm{Bu}$ modelden hesaplanan biyosorpsiyon kapasitesi değerleri ile deneysel olarak elde edilen kapasite değerleri uyum içerisindedir ve sonuç, biyosorpsiyon hızının biyosorban yüzeyindeki boşluklarla doğru orantılı arttığını düşündürmektedir.

3.4. Biyosorpsiyona başlangıç boyarmadde derişimi etkisi ve izoterm çalışmaları

Çalışmada biyokompozit sorban üzerine farklı başlangıç boyarmadde derişimlerinde AK1 ve RK2 biyosorpsiyonu gerçekleştirilmiş, sonuçlar Şekil 6 'da verilmiştir.

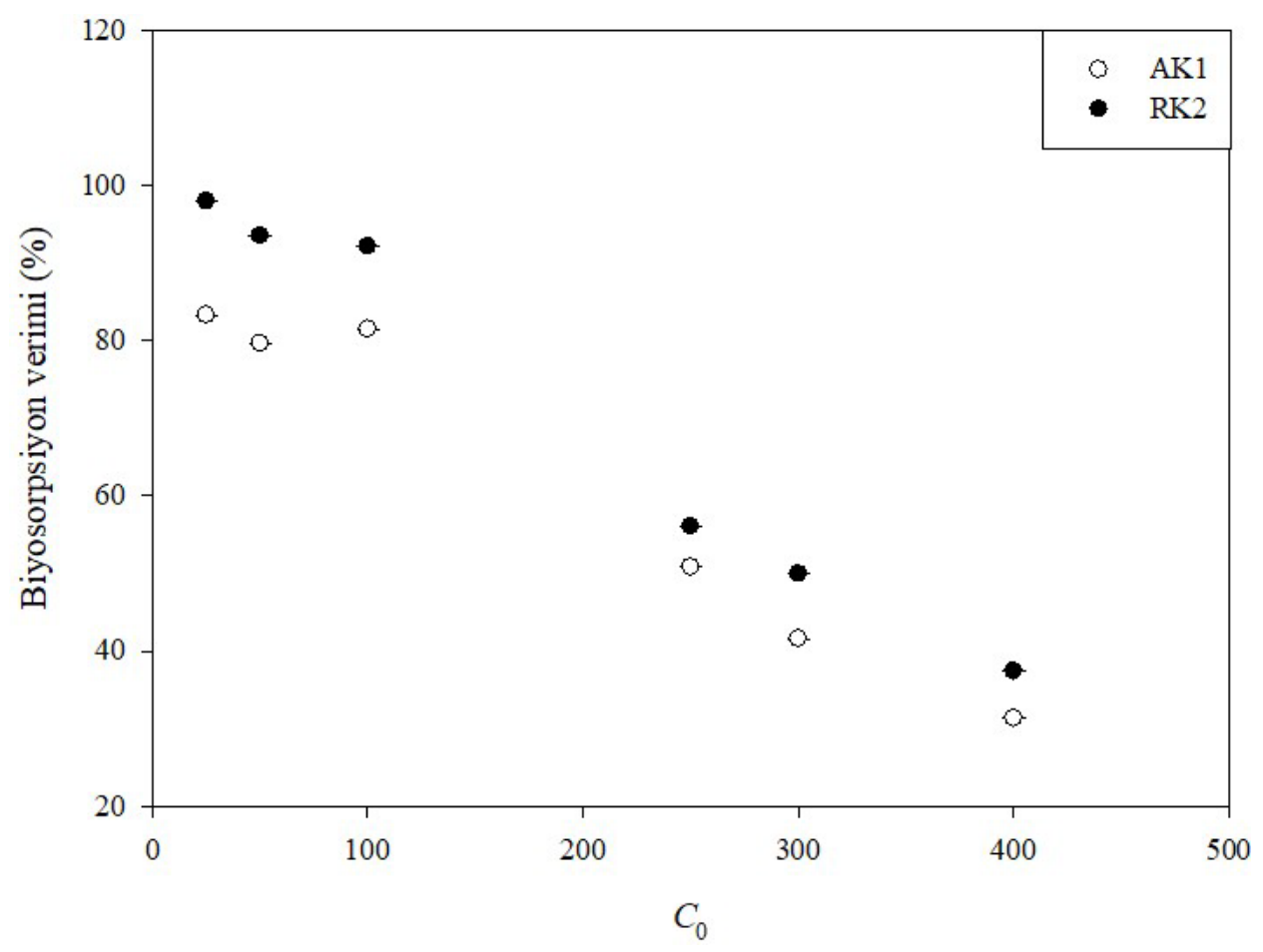

Şekil 6. Biyokompozit sorban ile AK1 ve RK2 biyosorpsiyonuna başlangıç boyarmadde derişiminin etkisi.

Şekil 6'da boyarmadde derişimlerinin $100 \mathrm{mg} \mathrm{L}^{-1}$, den $400 \mathrm{mg} \mathrm{L}^{-1}$ 'e artmasıly birlikte biyokompozit sorbanın biyosorpsiyon verimleri AK1 için $\% 83,29$ 'dan \%31,39'a; RK2 için ise \%97,97'den \%37,46'a düşmektedir. Düşük boyarmadde derişimlerinde, biyokompozit sorbanın yüzeyindeki aktif bağlanma bölgelerinin boyarmadde çözeltisindeki toplam iyon derişimine oranı yüksek olduğunda, tüm boyarmadde iyonları biyosorban ile etkileşim içindedir ve sulu ortamdan yükssek verimle uzaklaştırılabilmektedir (Öztürk vd., 2020).

Elde edilen denge biyosorpsiyon verileri ayrica genel izoterm grafiği şeklinde de sunulmuş ve doğrusal olmayan regresyon analizlerine dayalı izoterm modellemesi Şekil 7'de verilmiştir. 


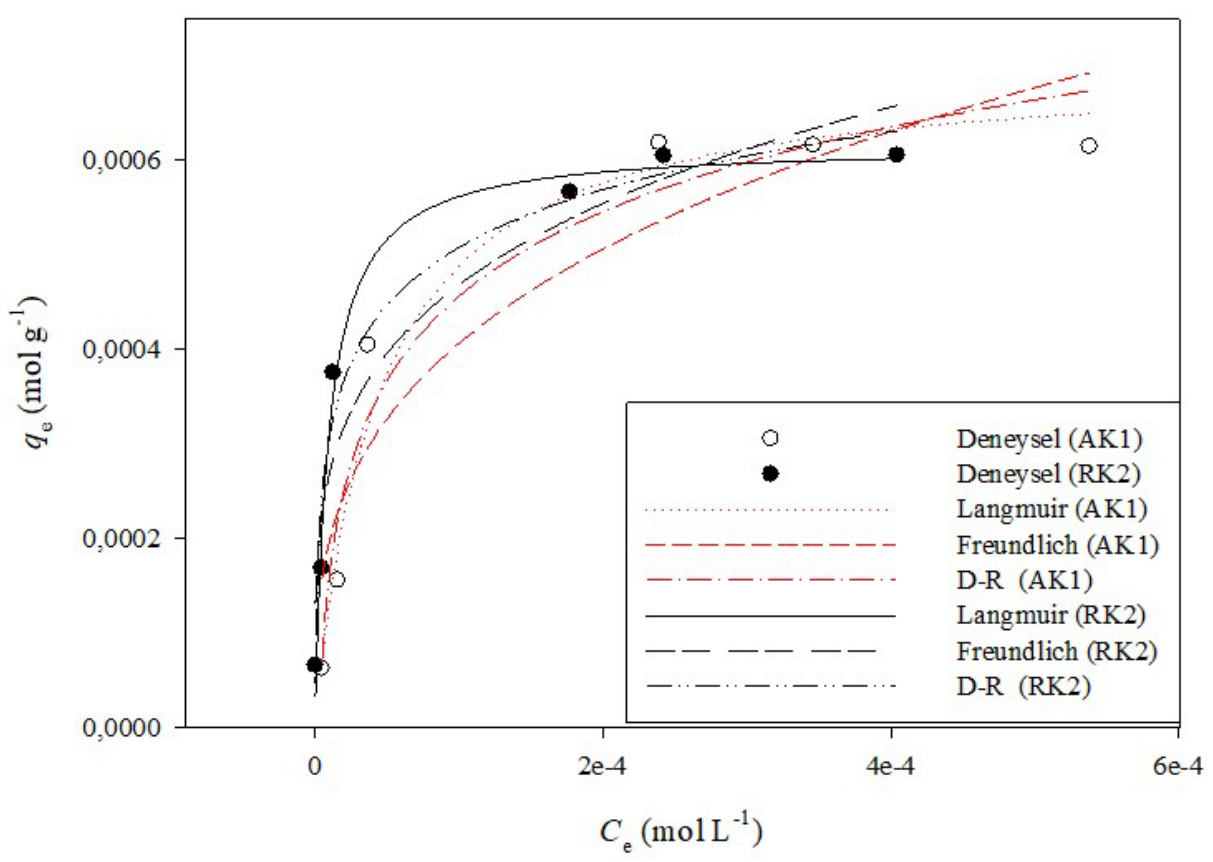

Şekil 7. Biyokompozit sorban ile AK1 ve RK2 biyosorpsiyonunun genel izoterm grafiği ve doğrusal olmayan regresyon analizleri.

Şekil 7 incelendiğinde denge boyarmadde derişiminin artmasıyla birlikte hem AK1 hem de RK2 için biyosorpsiyon kapasitelerinde artış olmuş, belli bir derişimden sonra da biyokompozit sorban maksimum biyosorpsiyon kapasitesine ulaşmıştır. $\mathrm{Bu}$ denge verilerinden yararlanarak AK1 ve RK2 biyosorpsiyon süreci Freundlich (Freundlich, 1906), Langmuir (Langmuir, 1918) ve D-R (Dubinin ve Radushkevich, 1947) izoterm modellerinin doğrusal olmayan eşitlikleri ile değerlendirilmiştir. $\mathrm{Bu}$ izoterm modellerine ait eşitlikler aşağıdaki gibi ifade edilmektedir:

Freundlich izoterm modeli:

$$
q_{\mathrm{d}}=K_{\mathrm{F}} C_{\mathrm{d}}^{1 / \mathrm{n}}
$$

Langmuir izoterm modeli:

$$
q_{\mathrm{d}}=\left(\frac{q_{\mathrm{m}} K_{\mathrm{L}} C_{\mathrm{d}}}{1+K_{\mathrm{L}} C_{\mathrm{d}}}\right)
$$

D-R izoterm modeli:

$$
q_{\mathrm{d}}=q_{\mathrm{m}} \cdot \exp \left(-\beta \varepsilon^{2}\right)
$$

$\mathrm{Bu}$ eşitliklerde $C_{\mathrm{d}}$ çözeltide kalan boyarmadde derişimi $\left(\mathrm{mol} \mathrm{L}^{-1}\right), q_{\mathrm{d}}\left(\mathrm{mol} \mathrm{g}^{-1}\right)$ biyokompozit sorban üzerine biyosorplanan boyarmadde miktarı, $K_{\mathrm{F}}\left(\left(\mathrm{mol} \mathrm{g}^{-1}\right)\left(\mathrm{mol} \mathrm{L}^{-1}\right)\right)^{-1 / \mathrm{n}} \quad$ Freundlich izoterm sabiti, $1 / \mathrm{n}$ heterojenite faktörüdür. $q_{\mathrm{mak}}$ maksimum tek tabakalı biyosorpsiyon kapasitesi, $K_{\mathrm{L}}\left(\mathrm{L} \mathrm{mol}^{-1}\right)$ biyosorpsiyonun serbest enerjisi ile ilgili Langmuir sabitidir. $q_{\mathrm{m}}$ biyosorpsiyon kapasitesi $\left(\mathrm{mol} \mathrm{g}^{-1}\right), \beta$ biyosorpsiyon serbest enerjisi ile ilgili D-R sabiti $\left(\mathrm{mol}^{2} \mathrm{~J}^{-2}\right)$ ve $\varepsilon$ Polanyi potansiyelidir $\left(\mathrm{kJ} \mathrm{mol}^{-1}\right)$. Bu izoterm eşitliklerinden hesaplanan izoterm parametreleri Tablo 2'de verilmektedir.

Tablo 2'de verilen izoterm parametrelerinden $r^{2}$ ve $F$ değerleri kıyaslandı̆̆ında biyokompozit sorban ile gerçekleştirilen biyosorpsiyon prosesinin her iki boyarmadde için daha çok Langmuir izoterm modeline uygun olduğu görülmektedir $(\mathrm{p}<0.05)$. Ayrıca S.E ve $p$ değerlerinin de bu modeli doğruladığ 1 söylenebilir. $\mathrm{Bu}$ doğrultuda biyokompozit sorban yüzeyinde her iki boyarmadde için tek tabakalı bir tutunmanın söz konusu olduğu ve biyosorpsiyonun homojen bir yüzeyde gerçekleştiği söylenebilir. Buradan elde edilen teorik maksimum biyosorpsiyon kapasiteleri (AK1 için $358.027 \mathrm{mg} \mathrm{g}^{-1}$; RK2 için $379.228 \mathrm{mg}$ $\mathrm{g}^{-1}$ ) deneysel olarak elde edilen maksimum biyosorpsiyon kapasiteleri (AK1 için $315.230 \mathrm{mg}$

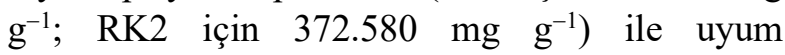
içerisindedir. Çalışmada AK1 ve RK2 giderimi için elde edilen maksimum biyosorpsiyon kapasite değerlerinin literatürdeki çeşitli sorbanların bu boyarmaddeler için bildirilen kapasite değerleriyle kıyaslanabilir düzeyde olduğu görülmektedir (Tablo 3). Ayrica, D-R izoterm modelinden hesaplanan $E$ değerlerine göre, her iki boyarmaddenin biyosorpsiyonunda fiziksel etkileşimin $\left(E<16 \mathrm{~kJ} \mathrm{~mol}^{-1}\right)$ rolünün olabileceği düşünülmektedir. 
Tablo 2. Biyokompozit sorban ile AK1 ve RK2 biyosorpsiyonlarına ait izoterm parametreleri

\begin{tabular}{|c|c|c|c|c|c|c|c|}
\hline \multicolumn{4}{|l|}{ AK1 } & \multicolumn{4}{|l|}{ RK2 } \\
\hline Parametre & & $t$ & $p$ & Parametre & & $t$ & $p$ \\
\hline \multicolumn{8}{|l|}{ Langmuir } \\
\hline$q_{\text {mak }}\left(\mathrm{mol} \mathrm{g}^{-1}\right)$ & $7.028 \times 10^{-4}$ & 5.693 & 0.0047 & $\begin{array}{l}q_{\mathrm{mak}} \\
\left(\mathrm{mol} \mathrm{g}^{-1}\right)\end{array}$ & $6.163 \times 10^{-4}$ & 5.149 & 0.0068 \\
\hline$K_{L}\left(\mathrm{~L} \mathrm{~mol}^{-1}\right)$ & $2.271 \times 10^{4}$ & 4,543 & 0.0105 & $\begin{array}{l}K_{L} \\
\left(\mathrm{~L} \mathrm{~mol}^{-1}\right)\end{array}$ & $10.311 \times 10^{4}$ & 4.469 & 0.0111 \\
\hline \multicolumn{4}{|c|}{$r^{2}: 0.978 ;$ S.E.: $0.0027 ; F: 173.553$} & \multicolumn{4}{|c|}{$r^{2}: 0.978 ;$ S.E.: $0.0025 ; F: 179.533$} \\
\hline \multicolumn{8}{|l|}{ Freundlich } \\
\hline$n$ & 3.152 & 3.809 & 0.0190 & $n$ & 4.102 & 5.043 & 0.0073 \\
\hline $\begin{array}{c}K_{F} \\
\left(\left(\mathrm{~mol} \mathrm{~g}^{-1}\right)\left(\mathrm{mol} \mathrm{L}^{-1}\right)\right)^{-1 / n}\end{array}$ & $7.6 \times 10^{-3}$ & 1.445 & 0.2220 & $K_{F}\left(\mathrm{~L} \mathrm{~g}^{-1}\right)$ & $4.4 \times 10^{-3}$ & 2.361 & 0.0776 \\
\hline \multicolumn{4}{|c|}{$r^{2}: 0.875 ;$ S.E.: $9.881 \times 10^{-5} ; F: 28.111$} & \multicolumn{4}{|c|}{$r^{2}: 0.929 ;$ S.E.: $7.027 \times 10^{-5} ; F: 52.275$} \\
\hline \multicolumn{8}{|l|}{$D-R$} \\
\hline$q_{\text {mak }}\left(\mathrm{mol} \mathrm{g}^{-1}\right)$ & $1.16 \times 10^{-3}$ & 11.314 & 0.0003 & $\begin{array}{l}q_{\text {mak }} \\
\left(\mathrm{mol} \mathrm{g}^{-1}\right)\end{array}$ & $1.3 \times 10^{-3}$ & 15.661 & $<0.0001$ \\
\hline$\beta\left(\mathrm{mol}^{2} \mathrm{~kJ}^{-2}\right)$ & 0.01 & 8.620 & 0.0010 & $\beta$ & $9.399 \times 10^{-3}$ & 11.231 & 0.0004 \\
\hline$E\left(\mathrm{~kJ} \mathrm{~mol}^{-1}\right)$ & 7.071 & & & $\begin{array}{l}E \\
\left(\mathrm{~kJ} \mathrm{~mol}^{-1}\right)\end{array}$ & 7.294 & & \\
\hline \multicolumn{4}{|c|}{$r^{2}: 0.949:$ S.E. $6.327 \times 10^{-5} ; F: 74.312$} & \multicolumn{4}{|c|}{$r^{2}: 0.969 ;$ S.E.: $4.621 \times 10^{-5} ; F: 126.124$} \\
\hline
\end{tabular}

Tablo 3. AK1 ve RK2 için farklı sorbanların sorpsiyon kapasitelerinin karşılaştırılması

\begin{tabular}{llll}
\hline Sorban materyali & Boyarmadde & $\begin{array}{c}\text { Sorpsiyon } \\
\text { kapasitesi }\left(\mathrm{mg} \mathrm{g}^{-1}\right)\end{array}$ & \multicolumn{1}{c}{ Kaynak } \\
\hline $\begin{array}{l}\text { Karboksimetilselüloz } \\
\text { (Manyetik grafen oksit kapl1) }\end{array}$ & AK1 & 47.456 & Sirajudheen vd., 2020 \\
Şeker pancarı (modifiye edilmiş) & AK1 & 98.2 & Tunali Akar vd., 2015 \\
Alünit-kitosan kompozit & AK1 & 588.75 & Tunali Akar vd., 2016 \\
Bentonit (modifiye edilmiş) & AK1 & 157.4 & Huang vd., 2017 \\
$\mathrm{Fe}_{3} \mathrm{O}_{4} /$ MIL-101 & AK1 & 142.9 & Wang vd., 2016 \\
Biyokompozit sorban & AK1 & 328.027 & Bu çalışma \\
Karboksimetilselüloz & RK2 & 47.887 & Sirajudheen vd., 2020 \\
(Manyetik grafen oksit kapl1) & & & \\
Şeker pancarı (modifiye edilmiş) & RK2 & 141.526 & Tunali Akar vd., 2013 \\
Alünit-kitosan kompozit & RK2 & 462.74 & Tunali Akar vd., 2016 \\
Karides kabuğu & RK2 & 166 & Thiyagarajan vd., 2017 \\
Agaricus bisporus (modifiye edilmiş) & RK2 & 141.53 & Akar ve Divriklioglu, 2010 \\
Biyokompozit sorban & RK2 & 379.228 & Bu çalışma \\
\hline
\end{tabular}

\subsection{Biyosorpsiyona iyonik şiddet etkisi}

Biyokompozit sorbanın üzerine AK1 ve RK2 biyosorpsiyonuna iyonik şiddetin etkisi belirlenen optimum koşullarda araştırılmıştır. $\mathrm{Bu}$ amaçla, boyarmadde çözeltilerine çözeltideki son tuz derişimleri $0.02 \mathrm{~mol} \mathrm{~L}^{-1}$ ile $0.2 \mathrm{~mol} \mathrm{~L}^{-1}$ arasında olacak şekilde $\mathrm{KNO}_{3}$ çözeltileri ilave edilmiş ve bu ortamda gerçekleştirilen biyosorpsiyon çalışmalarına ait sonuçlar Şekil 8'de verilmiştir. Şekil 8'de görüldüğü gibi $\mathrm{KNO}_{3}$ derişiminin artmasıyla birlikte her iki boyarmaddenin biyosorpsiyon verimi kademeli olarak azalmaktadır. 


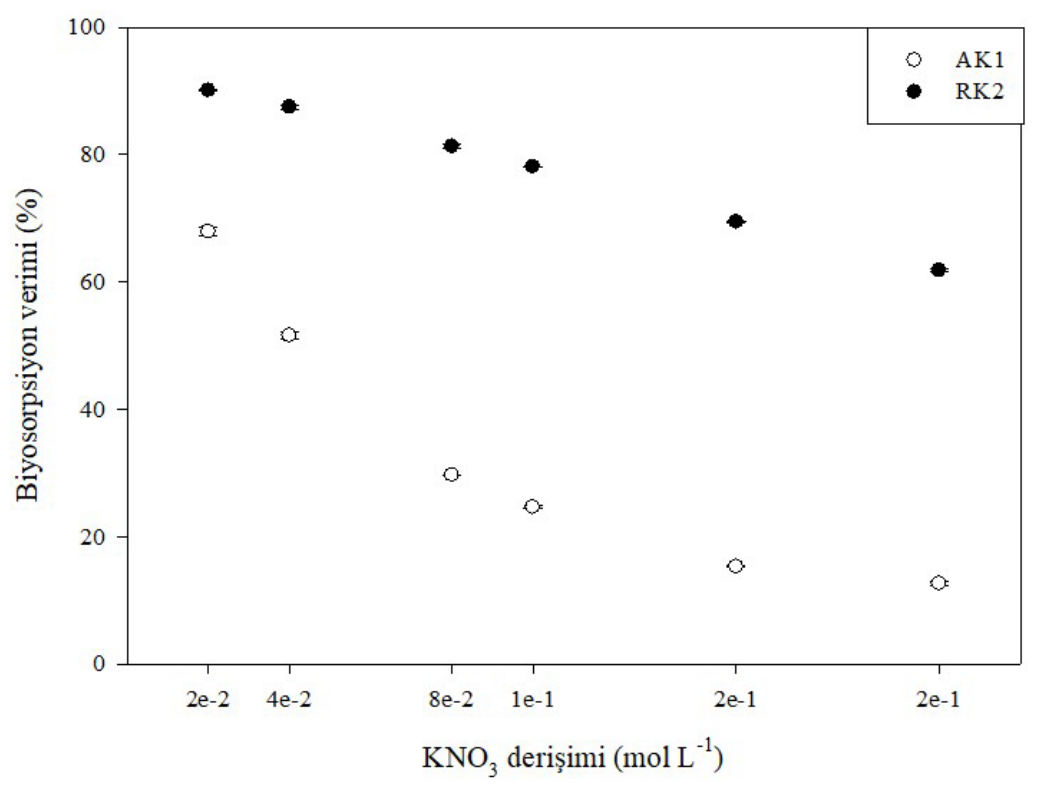

Şekil 8. Biyokompozit sorban ile AK1 ve RK2 biyosorpsiyonlarına iyonik şiddetin etkisi.

Ortamdaki tuz derişiminin $0.2 \mathrm{~mol} \mathrm{~L}^{-1}$ değerine ulaştığ1 noktada ise AK1 biyosorpsiyonunda yaklaş1k \%55; RK2 biyosorpsiyonunda ise yaklaşık \%28 azalma olmaktadır. Bu durum $\mathrm{NO}_{3}{ }^{-}$iyonları ile anyonik karakterli boyarmadde molekülleri arasında biyosorbanın fonksiyonel gruplarına bağlanmak adına gerçekleşen bir yarışma ile açıklanabilmektedir. Dolayısıyla yabanc1 anyonların ortamdaki varlığı AK1 ve RK2 biyosorpsiyon verimlerinde bir miktar düşüşe neden olmaktadir. Ayrica bu bulgular biyokompozit sorban yüzeyine AK1 ve RK2 boyarmaddelerin biyosorpsiyonunda daha önce de açıklanan elektrostatik etkileşimin rolünü de doğrulamaktadır.

\subsection{Karakterizasyon}

Olas1 biyokompozit sorban-boyarmadde etkileşimlerinin incelenmesi ve aynı zamanda immobilizasyon işleminin yeni biyosorban materyalde neden olduğu değişiklikleri açıklayabilmek amacıyla IR ve SEM analizleri gerçekleştirilmiştir. Doğal formdaki biyokütle, biyokompozit sorban ve boyarmaddelerin yüklendiği biyokompozit sorbana ait IR spektrumları Şekil 9'da verilmiştir.

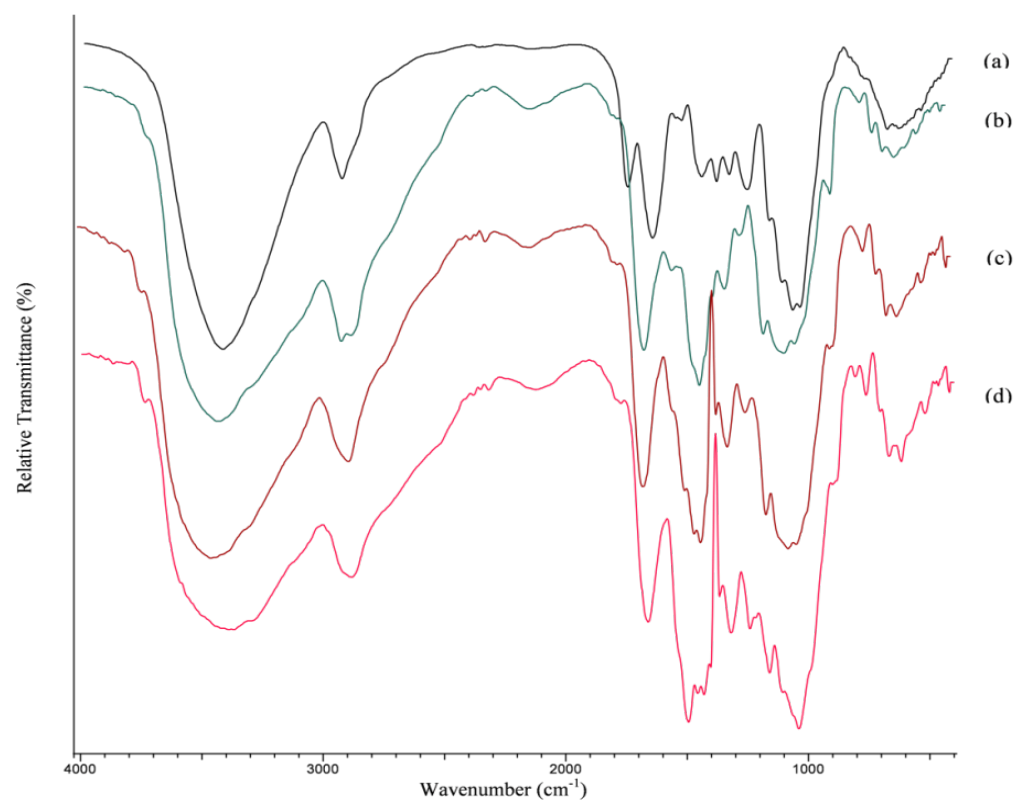

Şekil 9. Doğal biyosorban (a), Biyokompozit sorban (b), AK1 yüklü biyokompozit sorban (c), RK2 yüklü biyokompozit sorban (d) için IR spektrumları. 
Şekil 9'da $3420 \mathrm{~cm}^{-1}$ civarındaki geniş bantlar $-\mathrm{NH}$ ve $-\mathrm{OH}$ gruplarını göstermektedir. 2928 $\mathrm{cm}^{-1}$ 'deki bant, hidrokarbon zincirlerine ait $\mathrm{C}-\mathrm{H}$ gerilme titreşimleri, 1437 ve $1375 \mathrm{~cm}^{-1}$ 'deki bantlar ise bu gruba ait eğilme titreşimleri olarak değerlendirilebilir. $1744 \mathrm{~cm}^{-1}$ civarındaki bantlar karboksilatların karbonil gerilmesine işaret etmektedir. Amid kaynaklı karbonil gerilme titreşimi ve lignin içindeki aromatik $\mathrm{C}-\mathrm{C}$ gerilme titreşimi, surasıyla 1641 ve $1519 \mathrm{~cm}^{-1}$ de gözlenmiştir. $1323 \mathrm{~cm}^{-1}$ deki bant sellüloz kaynaklı $\mathrm{C}-\mathrm{H}$ eğilme titreșimi olarak değerlendirilmiștir. $1248 \mathrm{~cm}^{-1}$ civarındaki bandın ligninin $\mathrm{C}-\mathrm{O}$ gerilmesinden kaynaklandığ 1 düşünülmektedir. 1059 ve $1030 \mathrm{~cm}^{-1}$ civarında gözlenen gerilme titreşimleri ise $\mathrm{C}-\mathrm{O}$ grupları olarak yorumlanabilir. 1155 ve $1103 \mathrm{~cm}^{-1}$ deki bantlar ise $\mathrm{C}-\mathrm{O}-\mathrm{C}$ gerilmeleri ile açılanabilir (Tunali Akar vd., 2013). Kitosan ile immobilizasyondan sonra biyokompozit sorban yapısinda $2878 \mathrm{~cm}^{-1}$ de ortaya çıkan yeni pikin ise $\mathrm{C}-\mathrm{H}$ gruplarından kaynaklandığı düşünülmektedir. Yine immobilizasyon sürecinden sonra 1744, 1519 $\mathrm{cm}^{-1}$ civarındaki bantların kaybolduğu görülmüş, 1437 ve $1375 \mathrm{~cm}^{-1}$ civarındaki bantlarda ise kaymalar gözlenmiştir. Ayrıca $1155 \mathrm{~cm}^{-1}$ deki pik şiddetinde artış gözlenmiş ve $1026 \mathrm{~cm}^{-1}$ de yeni bir pik ortaya çıkmıştır. Bu şiddet artış1 ve yeni pik kitosanda bulunan $\beta-1,4-$ glikozidik bağlarından kaynaklanan $\mathrm{C}-\mathrm{O}$ gerilme titreşimleri ile ilişkilendirilebilir (Zeng vd., 2015). Buna ek olarak

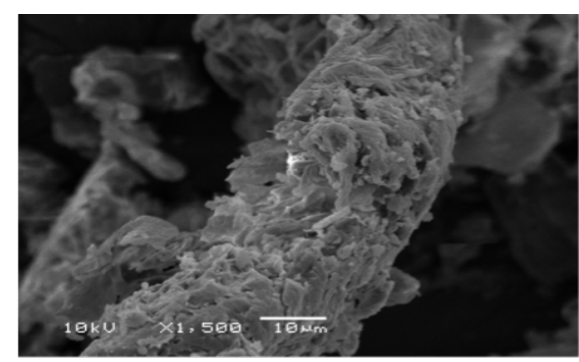

Doğal biyosorban

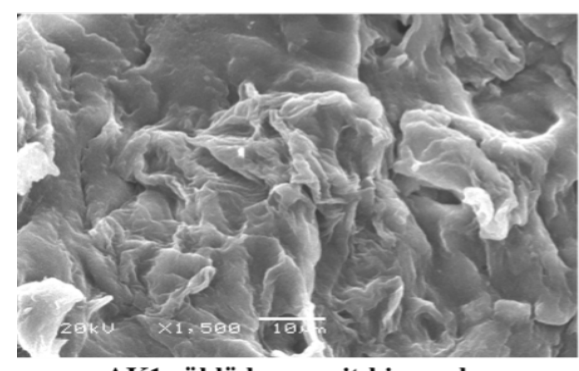

AK1 yüklü kompozit biyosorban
$910,700,650$ ve $561 \mathrm{~cm}^{-1}$ de yeni küçük şiddette bantlar ortaya çıkmış olup bunlar da sırasıyla $-\mathrm{OH}$ titreşimleri, düzlem dişı $\mathrm{NH}$ titreşimleri, düzlem dişı $\mathrm{OH}$ titreşimleri ve $-\mathrm{CH}$ titreşimleri olarak düşünülebilir (Zeng vd., 2015; Eddya vd., 2020). Biyosorpsiyon sürecinden sonra her iki boyarmadde için $2928 \mathrm{~cm}^{-1}$ 'deki bantın kaybolduğu görülmüştür. $\quad$ AK1 biyosorpsiyonundan sonra $1496 \mathrm{~cm}^{-1}$ de yeni bir bant ortaya çıkmıştır. Bu da boyarmaddenin azo grubu ile ilişkilendirilebilir. 1437 ve 1375 $\mathrm{cm}^{-1}$, deki bantların AK1 biyosorpsiyonundan sonra 1445 ve $1398 \mathrm{~cm}^{-1}$ 'e kaydığı görülmektedir. RK2 biyosorpsiyonundan sonra ise, $1500 \mathrm{~cm}^{-1}$ de yeni bir bant ortaya çıkmış, bu bant da benzer şekilde boyarmadde yapısındaki $-\mathrm{N}=\mathrm{N}$ gerilme titreşimleri ile açıklanabilir.

Ayrıca biyokompozit sorbanın yüzeyindeki asidik ve bazik grupları belirlemek amaciyla Boehm titrasyonu gerçekleştirilmiştir. Bu metoda göre, $\mathrm{NaOH}$ tüm asidik grupları (fenol, laktonik grup ve karboksilik asit), $\mathrm{Na}_{2} \mathrm{CO}_{3}$ karboksilik asit ve laktonları, $\mathrm{NaHCO}_{3}$ sadece karboksilik asitleri ve $\mathrm{HCl}$ de tüm bazik grupları nötralize etmektedir (Goertzen vd., 2010). Biyokompozit sorbanda karboksilik, fenol ve laktonik grup miktarları

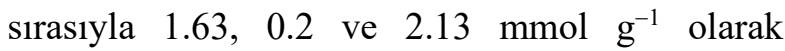
hesaplanırken, bazik grup $0.88 \mathrm{mmol} \mathrm{g}^{-1}$ olarak hesaplanmıştır. Bu sonuçlara göre biyokompozit sorbanın üzerinde asidik grupların bazik gruplardan daha fazla olduğu belirlenmiştir.

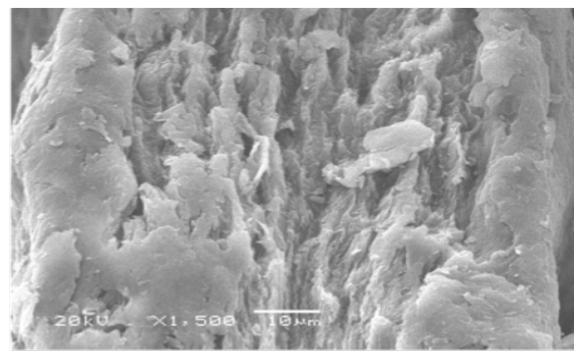

Kompozit biyosorban

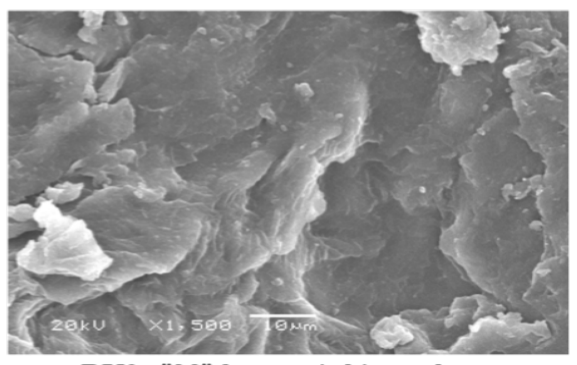

RK2 yüklü kompozit biyosorban

Şekil 10. Doğal biyosorban, biyokompozit sorban, AK1 yüklü biyokompozit sorban ve RK2 yüklü biyokompozit sorbanın yüzey görüntüleri.

Yine immobilizasyon işleminin yüzeysel etkisini görebilmek ve biyokompozit sorban yüzeyinde boyarmaddelerin biyosorpsiyonundan sonra olas1 değişiklikleri görsel açıdan değerlendirebilmek 
için taramalı elektron mikroskobu görüntülerinden yararlanılmıştır. $\mathrm{Bu}$ amaçla doğal biyokütle, biyokompozit sorban, AK1 ve RK2 yüklü biyokompozit sorbanın taramalı elektron mikroskobu ile kaydedilen $\times 1500$ büyütmedeki SEM görüntüleri alınmış ve Şekil 10'da sunulmuştur. Şekil 10'da görüldüğü gibi, doğal biyosorbanın yüzeyi pürüzlü ve gözenekli yapıdadır. Kitosan ile immobilizasyondan sonra oluşan biyokompozit sorbanın yüzeyi ise daha kaba ve kısmen pürüzlü yapıya sahiptir. AK1 ve RK2 biyosorpsiyonundan sonra ise biyokompozit sorbanın yüzeyindeki pürüzlü görünümün azaldığı ve yüzeyin daha düz bir zemine sahip olduğu görülmektedir. Bu sonuçlar, biyokompozit sorban yüzeyinin boyarmadde molekülleri ile örtüldügünü görsel olarak kanıtlamaktadır.

\section{Sonuçlar}

$\mathrm{Bu}$ çalışmada, bir endüstriyel tarımsal atık olan şeker pancarı posasının kitosan ile immobilize formu hazırlanmış ve bu yeni biyokompozitin alternatif bir kullanım alanında değerlendirmesi araştırılmıştır. Geliştirilen materyal tekstil endüstrisinde yaygın olarak kullanılan reaktif ve asidik boyarmaddelerden AK1 ve RK2'nin biyosorpsiyonu için kullanılmıştır. Optimize edilen biyosorpsiyon koşullarında oldukça kısa bir denge süresinde $(10 \mathrm{dk}) \mathrm{AK} 1$ için \%81.23; RK2 için ise $\% 86.79$ giderim verimlerine ulaşılmıştır. Kısa biyosorpsiyon denge süresinin yanında biyokompozit sorbanın yüksek derişimli tuz ortamında da biyosorpsiyon performans 1 sergileyebilmesi, tekstil atık sularının tuz içerikleri göz önüne alındığında pratik uygulamalar için bir diğer önemli avantajdır. Çalışmada AK1 ve RK2 biyosorpsiyon dinamikleri kinetik ve izoterm modelleriyle incelenmiş olup her iki boyarmadde için yalanc1-birinci-dereceden kinetik modeli ile ve Langmuir izoterm modeline uyum sağladığ gözlenmiştir. Teorik hesaplanan tek tabakalı maksimum biyosorpsiyon kapasitesi AK1 için $358.027 \mathrm{mg} \mathrm{g}^{-1}$ ve RK2 için ise $379.228 \mathrm{mg} \mathrm{g}^{-1}$ olarak hesaplanmıştır. Karakterizason çalışmalarında zeta potansiyeli, Boehm titrasyonu, IR ve SEM analizleri kullanılmış, biyosorpsiyonun karmaşık mekanizması açıklanmaya çalışılmıştır. Sonuçlar, geliştirilen biyokompozit sorbanın arıtım uygulamaları için ekonomik ve etkili bir alternatif olabileceğini göstermektedir.

\section{Kaynaklar}

Akar, T. and Divriklioglu, M. (2010). Biosorption applications of modified fungal biomass for decolorization of Reactive Red 2 contaminated solutions: Batch and dynamic flow mode studies.
Bioresource Technology, 101(19), 7271-7277. https://doi.org/10.1016/j.biortech.2010.04.044.

Akar, T., Arslan, S. and Akar, S. T. (2013). Utilization of Thamnidium elegans fungal culture in environmental cleanup: a reactive dye biosorption study. Ecological Engineering, 58, 363-370.

https://doi.org/10.1016/j.ecoleng.2013.06.026.

Akkaya, G. and Özer, A. (2005). Biosorption of Acid Red 274 (AR 274) on Dicranella varia: Determination of equilibrium and kinetic model parameters. Process Biochemistry, 40(11), 35593568.

https://doi.org/10.1016/j.procbio.2005.03.048.

Aksu, Z. and İşoğlu, İ. A. (2005). Removal of copper (II) ions from aqueous solution by biosorption onto agricultural waste sugar beet pulp. Process Biochemistry, 40(9), 3031-3044. https://doi.org/10.1016/j.procbio.2005.02.004.

Altundogan, H. S., Arslan, N. E. and Tumen, F. (2007). Copper removal from aqueous solutions by sugar beet pulp treated by $\mathrm{NaOH}$ and citric acid. Journal of Hazardous Materials, 149(2), 432439.

https://doi.org/10.1016/j.jhazmat.2007.04.008.

An, T., Zhou, L., Li, G., Fu, J. and Sheng, G. (2008). Recent patents on immobilized microorganism technology and its engineering application in wastewater treatment. Recent Patents on Engineering, 2(1), 28-35. https://doi.org/10.2174/187221208783478543.

Arslanoğlu, H. ve Tümen, F. (2015). Sitrik asitle modifiye edilmiş şeker pancarı küspesi ile sulu çözeltilerden $\mathrm{Pb}(\mathrm{II})$ ve $\mathrm{Cd}(\mathrm{II})$ giderilmesi. Fırat Üniversitesi Mühendislik Bilimleri Dergisi, 27(1), 85-99. https://dergipark.org.tr/en/pub/fumbd/issue/292 $53 / 313185$

Barka, N., Abdennouri, M. and Makhfouk, M. E. (2011). Removal of methylene blue and eriochrome black $\mathrm{T}$ from aqueous solutions by biosorption on Scolymus hispanicus L.: Kinetics, equilibrium and thermodynamics. Journal of the Taiwan Institute of Chemical Engineers, 42(2), 320-326. https://doi.org/10.1016/j.jtice.2010.07.004.

Bouras, H. D., Yeddou, A. R., Bouras, N., Hellel, D., Holtz, M. D., Sabaou, N., Chergui, A. and Nadjemi, B. (2017). Biosorption of Congo red dye by Aspergillus carbonarius M333 and Penicillium glabrum Pg1: Kinetics, equilibrium and thermodynamic studies. Journal of the Taiwan Institute of Chemical Engineers, 80, 915 923. https://doi.org/10.1016/j.jtice.2017.08.002.

Castro, L., Blázquez, M. L., González, F., Muñoz, J. A. and Ballester, A. (2017). Biosorption of Zn (II) 
from industrial effluents using sugar beet pulp and $F$. vesiculosus: From laboratory tests to a pilot approach. Science of the Total Environment, 598, 856-866. https://doi.org/10.1016/j.scitotenv.2017.04.138.

Crini, G. and Badot, P. M. (2008). Application of chitosan, a natural aminopolysaccharide, for dye removal from aqueous solutions by adsorption processes using batch studies: a review of recent literature. Progress in Polymer Science, 33(4), 399-447.

https://doi.org/10.1016/j.progpolymsci.2007.11. 001.

De-Bashan, L. E. and Bashan, Y. (2010). Immobilized microalgae for removing pollutants: review of practical aspects. Bioresource Technology, 101(6), 1611-1627. https://doi.org/10.1016/j.biortech.2009.09.043.

Demiral, H. and Gündüzoğlu, G. (2010). Removal of nitrate from aqueous solutions by activated carbon prepared from sugar beet bagasse. Bioresource Technology, 101(6), 1675-1680. https://doi.org/10.1016/j.biortech.2009.09.087.

Dronnet, V. M., Renard, C. M. G. C., Axelos, M. A. V. and Thibault, J. F. (1997). Binding of divalent metal cations by sugar-beet pulp. Carbohydrate Polymers, 34(1-2), 73-82. https://doi.org/10.1016/S0144-8617(97)000556.

Dubinin, M. M. and Radushkevich, L. V. (1947). Evaluation of microporous materials with a new isotherm. In Dokl. Akad. Nauk. SSSR, 55, 331334.

Eddya, M., Tbib, B. and Khalil, E. H. (2020). A comparison of chitosan properties after extraction from shrimp shells by diluted and concentrated acids. Heliyon, 6(2), e03486. https://doi.org/10.1016/j.heliyon.2020.e03486.

Freundlich, H. (1907). Über die adsorption in lösungen. Zeitschrift für physikalische Chemie, 57(1), 385470.

Girijan, S. and Kumar, M. (2019). Immobilized biomass systems: an approach for trace organics removal from wastewater and environmental remediation. Current Opinion in Environmental Science \& Health, 12, 18-29. https://doi.org/10.1016/j.coesh.2019.08.005.

Goertzen, S. L., Thériault, K. D., Oickle, A. M., Tarasuk, A. C. and Andreas, H. A. (2010). Standardization of the Boehm titration. Part I. $\mathrm{CO} 2$ expulsion and endpoint determination. Carbon, 48(4), 1252-1261. https://doi.org/10.1016/j.carbon.2009.11.050.
Ho, Y. S. and McKay, G. (1999). Pseudo-second order model for sorption processes. Process Biochemistry, 34(5), 451-465. https://doi.org/10.1016/S0032-9592(98)001125.

Huang, Z., Li, Y., Chen, W., Shi, J., Zhang, N., Wang, X., Li, Z., Gao, L. and Zhang, Y. (2017). Modified bentonite adsorption of organic pollutants of dye wastewater. Materials Chemistry and Physics, 202, 266-276. https://doi.org/10.1016/j.matchemphys.2017.09. 028.

Khan, M. M. R., Sahoo, B., Mukherjee, A. K. and Naskar, A. (2019). Biosorption of acid yellow-99 using mango (Mangifera indica) leaf powder, an economic agricultural waste. SN Applied Sciences, 1(11), 1-15. https ://doi.org/10.1007/s4245 2-019-1537-6.

Kumari, K. and Abraham, T. E. (2007). Biosorption of anionic textile dyes by nonviable biomass of fungi and yeast. Bioresource Technology, 98(9), 1704-1710. https://doi.org/10.1016/j.biortech.2006.07.030.

Lagergren, S. (1898). Zur theorie der sogenannten adsorption geloster stoffe. Kungliga svenska vetenskapsakademiens. Handlingar, 24, 1-39.

Langmuir, I. (1918). The adsorption of gases on plane surfaces of glass, mica and platinum. Journal of the American Chemical Society, 40(9), 13611403.

Nawaz, S., Bhatti, H. N., Bokhari, T. H. and Sadaf, S. (2014). Removal of Novacron Golden Yellow dye from aqueous solutions by low-cost agricultural waste: Batch and fixed bed study. Chemistry and Ecology, 30(1), 52-65. https://doi.org/10.1080/02757540.2013.841898.

Ngah, W. W., Ab Ghani, S. and Kamari, A. (2005). Adsorption behaviour of $\mathrm{Fe}$ (II) and $\mathrm{Fe}$ (III) ions in aqueous solution on chitosan and cross-linked chitosan beads. Bioresource Technology, 96(4), 443-450.

https://doi.org/10.1016/j.biortech.2004.05.022.

Özer, A., Tanyildizi, M. S. and Tümen, F. (1998). Study of cadmium adsorption from aqueous solution on activated carbon from sugar beet pulp. Environmental Technology, 19(11), 1119-1125. https://doi.org/10.1080/09593331908616770.

Öztürk, M , Yıldız, S. ve Aslan, Ş . (2020). Nikel (II) iyonlarinin atık çay'a biyosorpsiyonu: denge, kinetik ve termodinamik çalımaları. Mühendislik Bilimleri ve Tasarm Dergisi, 8(4), 985-998. https://doi.org/10.21923/jesd.742918.

Pehlivan, E., Cetin, S. and Yanık, B. H. (2006). Equilibrium studies for the sorption of zinc and 
copper from aqueous solutions using sugar beet pulp and fly ash. Journal Of Hazardous Materials, $\quad$ 135(1-3), 193-199. https://doi.org/10.1016/j.jhazmat.2005.11.049.

Rangabhashiyam, S., Anu, N. and Selvaraju, N. (2013). Sequestration of dye from textile industry wastewater using agricultural waste products as adsorbents. Journal of Environmental Chemical Engineering, $\quad 1(4), \quad 629-641$. https://doi.org/10.1016/j.jece.2013.07.014.

Safa, Y. and Bhatti, H. N. (2011). Adsorptive removal of direct textile dyes by low cost agricultural waste: Application of factorial design analysis. Chemical Engineering Journal, 167(1), 35-41. https://doi.org/10.1016/j.cej.2010.11.103.

Sirajudheen, P., Nikitha, M. R., Karthikeyan, P. and Meenakshi, S. (2020). Perceptive removal of toxic azo dyes from water using magnetic $\mathrm{Fe} 3 \mathrm{O} 4$ reinforced graphene oxide-carboxymethyl cellulose recyclable composite: Adsorption investigation of parametric studies and their mechanisms. Surfaces and Interfaces, 21, 100648.

https://doi.org/10.1016/j.surfin.2020.100648.

Subramani, S. E. and Thinakaran, N. (2017). Isotherm, kinetic and thermodynamic studies on the adsorption behaviour of textile dyes onto chitosan. Process Safety and Environmental Protection, 106, 1-10. https://doi.org/10.1016/j.psep.2016.11.024.

Şenol, Z. M., Gürsoy, N., Şimşek, S., Özer, A. and Karakuş, N. (2020). Removal of food dyes from aqueous solution by chitosan-vermiculite beads. International Journal of Biological Macromolecules, $\quad 148, \quad 635-646$. https://doi.org/10.1016/j.ijbiomac.2020.01.166.

Thiyagarajan, E., Saravanan, P., Saranya, P., Gandhi, N. N. and Renganathan, S. (2017). Biosorption of reactive red 2 using positively charged Metapenaeus monoceros shells. Journal of Saudi Chemical Society, 21, S1-S6. https://doi.org/10.1016/j.jscs.2013.05.004.

Tunalı Akar, S., Yilmazer, D., Celik, S., Balk, Y. Y. and Akar, T. (2013). On the utilization of a lignocellulosic waste as an excellent dye remover: Modification, characterization and mechanism analysis. Chemical Engineering Journal, 229, 257-266. https://doi.org/10.1016/j.cej.2013.06.009.

Tunalı Akar, S., Yilmazer, D., Celik, S., Balk, Y. Y. and Akar, T. (2015). Effective biodecolorization potential of surface modified lignocellulosic industrial waste biomass. Chemical Engineering Journal, 259, 286-292. https://doi.org/10.1016/j.cej.2014.07.112.
Tunalı Akar, S., San, E. and Akar, T. (2016). Chitosanalunite composite: an effective dye remover with high sorption, regeneration and application potential. Carbohydrate Polymers, 143, 318-326. https://doi.org/10.1016/j.carbpol.2016.01.066.

ud Din, M., Bhatti, H. N., Yasir, M. and Ashraf, A. (2016). Direct dye biosorption by immobilized barley husk. Desalination and Water Treatment, 57(20), 9263-9271. https://doi.org/10.1080/19443994.2015.1027962

Vakili, M., Rafatullah, M., Salamatinia, B., Abdullah, A. Z., Ibrahim, M. H., Tan, K. B., Gholami, Z. and Amouzgar, P. (2014). Application of chitosan and its derivatives as adsorbents for dye removal from water and wastewater: A review. Carbohydrate Polymers, 113, 115-130. https://doi.org/10.1016/j.carbpol.2014.07.007.

Vučurović, V. M., Razmovski, R. N. and Tekić, M. N. (2012). Methylene blue (cationic dye) adsorption onto sugar beet pulp: equilibrium isotherm and kinetic studies. Journal of the Taiwan Institute of Chemical Engineers, 43(1), 108-111. https://doi.org/10.1016/j.jtice.2011.06.008.

Wang, T., Zhao, P., Lu, N., Chen, H., Zhang, C. and Hou, X. (2016). Facile fabrication of $\mathrm{Fe}_{3} \mathrm{O}_{4} / \mathrm{MIL}$ $101(\mathrm{Cr})$ for effective removal of acid red 1 and orange $\mathrm{G}$ from aqueous solution. Chemical Engineering Journal, 295, 403-413. https://doi.org/10.1016/j.cej.2016.03.016.

Wase, D. A. J. and Forster, C. F. (Eds.). (1997). Biosorbents for Metal Ions. UK: CRC Press.

Yang, Y., Wang, G., Wang, B., Li, Z., Jia, X., Zhou, Q. and Zhao, Y. (2011). Biosorption of Acid Black 172 and Congo Red from aqueous solution by nonviable Penicillium YW 01: Kinetic study, equilibrium isotherm and artificial neural network modeling. Bioresource Technology, 102(2), 828-834. https://doi.org/10.1016/j.biortech.2010.08.125.

Zeng, L., Chen, Y., Zhang, Q., Guo, X., Peng, Y., Xiao, H., Chen, X. and Luo, J. (2015). Adsorption of $\mathrm{Cd}$ (II), $\mathrm{Cu}$ (II) and $\mathrm{Ni}$ (II) ions by cross-linking chitosan/rectorite nano-hybrid composite microspheres. Carbohydrate Polymers, 130, 333-343. https://doi.org/10.1016/j.carbpol.2015.05.015.

Zhou, Y., Lu, J., Zhou, Y. and Liu, Y. (2019). Recent advances for dyes removal using novel adsorbents: a review. Environmental Pollution, 252 , 352-365. https://doi.org/10.1016/j.envpol.2019.05.072. 